\title{
ITINERARIO ARQUEOLÓGICO DE LOS DÓLMENES DE SEDANO (BURGOS)
}

\author{
AN ARCHAEOLOGICAL ITINERARY OF THE CHAMBERED TOMBS OF SEDANO \\ (BURGOS)
}

GERMÁN DELIBES DE CASTRO (*)

\section{RESUMEN}

Tras la excavación en los años 80 de una serie de sepulcros megalíticos de la comarca de Sedano, en La Lora Burgalesa, la Junta de Castilla y León ha promovido la iniciativa de recuperar los más vistosos y de crear en torno a ellos un proyecto de difusión cultural. Ello ha exigido la restauración de tales monumentos y la creación de una infraestructura didáctica (la edición de una guía y la creación de un Aula en Sedano) que está previsto entren en funcionamiento a partir del verano del año 2000.

\begin{abstract}
Since the excavations carried out in the 80's, focused on several megalithic burials located in the Sedano area (La Lora, Burgos), the Junta de Castilla y León has promoted the enterprise of restoring the most attractive of them and creating around them a cultural diffusion project. This aim implies the restoration of these monuments and the creation of a didactic infraestructure (publication of a guidebook and building of a small museum in Sedano) which will be brought into service by summer 2000.
\end{abstract}

Palabras claves: Patrimonio histórico. Norte de Burgos. Megalitos. Restauración. Interpretación.

Key words: Historical heritage. Northern Burgos. Megaliths. Restoration. Interpretation.

(*) Facultad de Filosofía y Letras. Universidad de Valladolid. Plaza del Campus s/n. 47011 Valladolid. Correo electrónico: delibes@fyl.uva.es

El artículo fue remitido en su versión final el 28-IX-2000.

\section{EL ESPACIO FÍSICO DE LA LORA BURGALESA Y LA HISTORIA DE LA INVESTIGACIÓN DE SUS MONUMENTOS MEGALÍTICOS}

La monótona altiplanicie de La Lora, en el Noroeste de la provincia de Burgos (Fig. 1), caracterizada por unos suelos pobres, por un riguroso clima, muy frío en invierno, y, de resultas de ambas circunstancias, por un modesto tapiz vegetal, no reune condiciones especialmente favorables para la ocupación humana lo que sin duda hubo de influir en la escasa atracción que ejerció en las comunidades prehistóricas. Llevado por esta convicción, Clark (Clark y Apellániz, 1979) aseguraba hace todavía no muchos años que este áspero espacio burgalés pudo haber permanecido prácticamente sin habitar hasta la Edad del Hierro, opinión, sin embargo, hoy imposible de suscribir una vez reconocida la entidad de la impronta megalítica en la comarca e, inclusive, la huella de un sustrato anterior, del tránsito Pleistoceno-Holoceno, en la Cueva del Níspero, en Orbaneja del Castillo (Corchón, 1989).

La historia de la investigación de los dólmenes de La Lora es breve y relativamente joven. Las más antiguas noticias sobre ellos datan de 1950 y se deben a C. Robledo (1954) y L. Huidobro (1957), descubridores del sepulcro de corredor del Moreco, en Huidobro. Habrá de transcurrir desde entonces casi un cuarto de siglo para que tenga lugar la primera excavación de uno de tales monumentos, llevada a cabo por Osaba, Abásolo, Uríbarri y Liz (1971) en La Cotorrita, Porquera de Butrón. Y las pesquisas no cobrarán verdadero impulso sino mediada la década de los 80 con el desarrollo de un proyecto de investigación en el que, valiéndonos de prospección y excavaciones, M. Rojo y el que sus- 


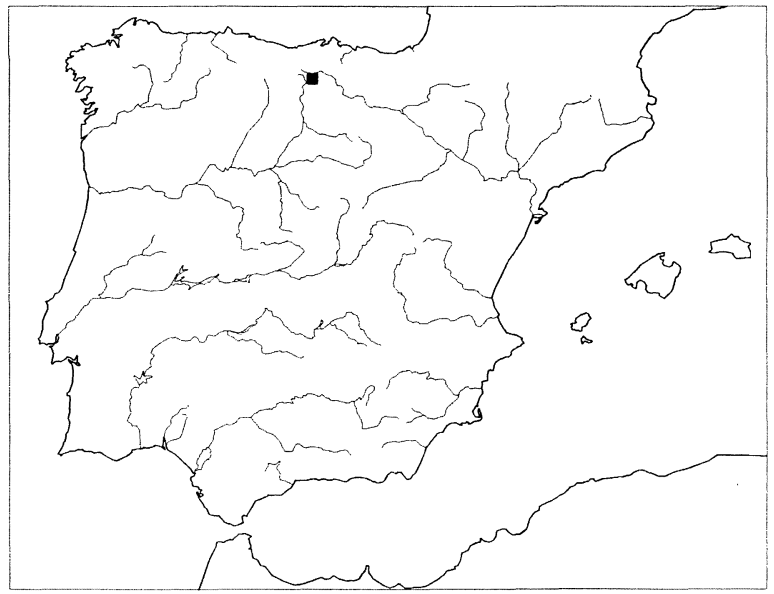

Fig. 1. Localización de la comarca de Sedano, en el Norte de Burgos.

cribe nos planteamos estudiar las variaciones experimentadas por los megalitos, a lo largo de su trayectoria -casi un milenio-, en los terrenos de la arquitectura, de los ajuares, del ritual y de la territorialidad, sin dejar de mostrar interés por la impronta que previsiblemente dejaron en el paisaje quienes los utilizaron.

Las referidas actuaciones, que han aportado un copioso caudal de datos, base de numerosos trabajos científicos, también han supuesto una amenaza para la supervivencia de las ruinas de los monumentos que se iban descubriendo, como consecuencia de la propia naturaleza destructiva de las labores arqueológicas. El problema no se planteaba en el caso, bastante común, de los dólmenes literalmente arrasados por los buscadores de tesoros de todas las épocas de la Historia, ya que se les devolvía acto seguido su original aspecto tumular, sepultándolos de nuevo, pero sí en el de los yacimientos de mayor empaque o relevancia monumental cuya exhibición, siquiera momentánea, parecía inexcusable. Advertido el problema, se consideró por momentos la posibilidad de aplicarles idéntica medida que a aquellos mas, a la postre, la Dirección General de Patrimonio y Promoción Cultural de la Junta de Castilla y León adoptó la decisión de recuperarlos para su difusión, surgiendo de allí la idea del Itinerario.

En este sentido, los restos arquitectónicos descubiertos, erigidos ya en Patrimonio Inmueble, han pasado a ser auténticos "lugares arqueológicos" o pequeños museos al aire libre, siguiendo uno de los procedimientos más extendidos para la presentación al público de este tipo de documentos y dan- do sentido, como se ha hecho en otros muchos lugares de Castilla y León (Casa et alii, 1998: 275-6), al espíritu de la Ley de Patrimonio Histórico Español que, en su preámbulo, insiste en la necesidad de facilitar a los ciudadanos el acceso y disfrute de los bienes culturales. Una iniciativa que no tiene un excesivo coste pero sí obliga a invertir en labores de consolidación de ruinas, a habilitar una mínima infraestructura (de acogida de visitantes e información) y a la inexcusable edición de unas guías que faciliten la interpretación de los restos, máxime cuando éstos, como sucede en toda "ruta arqueológica", muestran una acusada dispersión.

Los yacimientos atendidos han sido cinco, en otros tantos municipios o pedanías -El Moreco en Huidobro, Las Arnillas en Moradillo de Sedano, La Cotorrita en Porquera de Butrón, Valdemuriel en Tubilla del Agua y La Cabaña en Sargentes de la Lora-, y han sido seleccionados en atención esencialmente a dos criterios: uno, el porte o la monumentalidad, pues no en vano se trata de transmitir al público la lección de que el megalitismo fué la primera gran arquitectura de la historia, y otro la viabilidad del acceso (Fig. 2). Esta última y no otra circunstancia ha sido determinante para excluir, por ejemplo, los dólmenes simples de Fuente Pecina, en Sedano, cuando tan interesante hubieramos considerado utilizarlos como contrapunto de los, en esta zona omnipresentes, sepulcros de corredor. Y, en el extremo contrario, habrá que reconocer que se ha forzado un tanto la filosofía de la selección en el caso de Las Arnillas, el más imponente y mejor conservado de los megalitos sedaneses, por cuanto llegar a él supone al día de hoy transitar por un largo y penoso camino. A comienzos de la década de los 90 , los cinco monumentos reseñados fueron objeto de un proyecto de restauración dirigido por el arquitecto I. Represa Bermejo, que materializaría la empresa Ortega S.A. de Burgos con el apoyo de los arqueólogos O. Arellano Hernández y A. Ruiz de Marco. Y a finales de 1998 se adjudicó al Gabinete Arquetipo, una vez más por parte de la Junta de Castilla y León, una propuesta de señalización y deAulaArqueológica de los dólmenes de la Lora. El compromiso de entrega de esta última antes del verano del año 2000 permite augurar que para tales fechas el Itinerario de los dólmenes de Sedano habrá adquirido gran parte de su definitiva configuración, dejando de ser, por fin, sólo un proyecto. Atrás queda una larga y no siempre fácil labor dedicada a un empeño del que, por invitación de Trabajos de Prehistoria, nos ha correspondido es- 


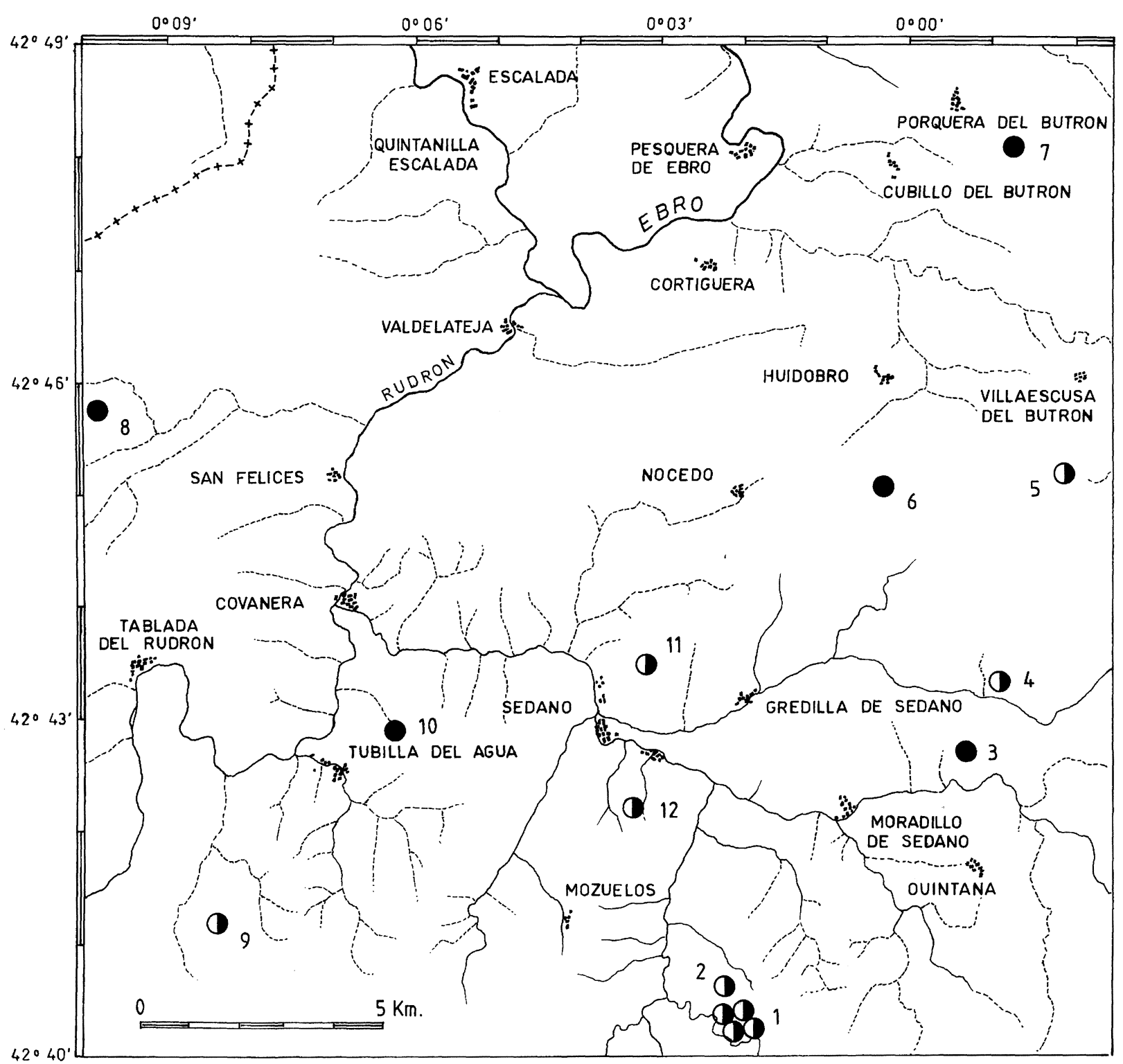

Fig. 2. Sepulcros megalíticos excavados en el área de Sedano (Burgos). Los puntos completamente oscuros se corresponden con los dólmenes del Itinerario.

cribir, pero que nunca hubiera llegado a fraguar sin el empuje investigador de nuestro compañero M.A. Rojo Guerra (1), sin el interés y la perseverancia de J. del Val Recio y J.J. Fernández Moreno, técnicos del Servicio de Arqueología de la Junta de Castilla y León, sin el buen hacer restaurador de I. Represa Bermejo ni sin el apoyo, siempre generoso, de los arqueólogos de Arquetipo. Nuestra mayor gratitud a todos ellos.

(1) Autor de la Tesis Doctoral, inédita, El fenómeno megalítico en La Lora burgalesa, defendida en la Universidad de Valladolid el curso 1991-1992.

\section{EL CONOCIMIENTO CIENTÍFICO, TRANSFONDO INEXCUSABLE DEL ITINERARIO}

En un momento en que tan poca sensibilidad existe hacia la investigación básica -sirva como ejemplo la mezquina filosofía de la convocatoria del Plan Nacional de I+D+I (2000-2003), tan incomprensiva con el trabajo científico no aplicado y, en consecuencia, con el cultivo de las Humanidades$o$ en el que no se duda en acometer excavaciones que persiguen la casi sola exhumación de ruinas re- 
cuperables patrimonialmente, sin recapacitar sobre lo que dichos trabajos suponen de destrucción de fuentes históricas potenciales, la perogrullada de este epígrafe deja de serlo tanto: La Arqueología, además de otras muchas cosas complementarias, es por encima de todo una disciplina de análisis histórico cuyo principal objetivo es generar conocimiento. A partir de ahí, igualmente importante es asumir otras realidades como que el Arqueólogo está socialmente obligado a rendir cuentas ante una ciudadanía que ha hecho posible su trabajo o como que la sociedad tiene derecho a obtener alguna clase de beneficio -en este caso informativo y patrimonial, a través de la divulgación de resultados y de presentar al público sus descubrimientos- del trabajo del excavador (Criado, 1996; Ruiz Zapatero, 1996). En cualquier caso, siempre el conocimiento científico como telón de fondo; una información sobre la que apoyar el proyecto didáctico que, en nuestro caso, trata de tomar como principal anclaje o punto de referencia los más conspícuos monumentos dolménicos de La Lora burgalesa.

La percepción de nuestros yacimientos no comporta excesiva dificultad para un observador más o menos avezado. Por sistema se instalan en los llanos rotundos de la paramera, eludiendo los valles de una red fluvial fuertemente encajada, y ello, junto con el característico volumen troncocónico o en casquete esférico de sus túmulos, les hace destacar con relativa facilidad en los horizontes abiertos de la planicie. Ese es el emplazamiento-tipo de los dólmenes de la comarca de Sedano, las austeras y uniformes alturas del páramo, lo que representa un contraste radical con la ubicación de los caseríos de los pueblos actuales, siempre establecidos en los estrechos corredores deprimidos de los ríos. Los túmulos, además, propenden a manifestarse más o menos aislados, nos atreveríamos a decir que constituyendo en cada caso el cementerio de un territorio relativamente bien individualizado por las quebradas de los valles mayores (Rojo, 1994). Son muy frecuentes los casos de un único dolmen por cada páramo (Ciella, Mozuelos, Tubilla, Nocedo, Los Altos), lo que sin embargo no sucede con absoluta seguridad en el sedanés de Fuente Pecina, sobre el valle de Las Hazas, donde se acredita una concentración muy clara de cuatro monumentos, que se distribuyen formando los ángulos de un polígono cuyo lado mayor no supera los $250 \mathrm{~m}$.

En este caso se trata, empero, de monumentos megalíticos de porte reducido y -como veremosanteriores a los más vistosos y de mayor tamaño.
Estos últimos, que son la mayoría de los recuperados para el Itinerario, revisten inexcusablemente la forma de sepulcros de corredor (Las Arnillas, El Moreco, La Cotorrita, La Cabaña) y subyacen a túmulos más o menos circulares de hasta $30 \mathrm{~m}$ de diámetro y más de $2 \mathrm{~m}$ de altura. Sus cámaras, construidas con bloques de caliza fundamentalmente sin desbastar, cuyas canteras nunca están lejos para suerte de quienes las hubieron de transportar, son poligonales de acusada tendencia circular, con nunca más de 1,5 $\mathrm{m}$ de radio, y han perdido hoy su cubierta primitiva que debió ser de madera y ramaje pues no existe la menor huella de un cierre monolítico plano ni de otras soluciones en aparejo pequeño, de piedra en seco, como la que sí se arbitró en algún tramo -sobre todo a partir de cierta altura- del pasillo de Las Arnillas (Fig. 3). Los corredores de entrada, orientados por lo general a naciente, vuelven a construirse con el mismo tipo de ortostatos aunque ahora invariablemente apaisados, para recibir en este caso una auténtica cubierta megalítica, de bloques adintelados, que sólo ha sobrevivido en buenas condiciones en La Cabaña y en Las Arnillas (Delibes y Rojo, 1998). En cuanto a los túmulos, según se ha podido comprobar en El Moreco o La Cabaña, lejos de ser la improvisada acumulación de escombros y tierra que tan frecuentemente se les supone, dan muestras de una meditada y compleja estructura-coronas pericamerales, círculos peristalíticos, corazas casi superficialesllamada a proteger ese esqueleto de bloques en precario equilibrio que no dejan de ser, pese a su magnificencia, las construcciones megalíticas (Delibes y Rojo, 1988).

En el extremo opuesto, en cuanto a monumentalidad, se sitúan los dólmenes simples, también de planta poligonal (paracircular en Pecina II; en forma de cofre o cista en Villaescusa) pero sin pasillo, y los transicionales (Valdemuriel, San Quirce, tal vez Pecina I), que aunan corredores más o menos desarrollados y cámaras de porte modesto y que, como ha puesto en evidencia una prolija serie de dataciones absolutas, antecedieron en el tiempo a los grandes túmulos (Delibes y Rojo, 1997). La exhaustiva prospección del entorno más próximo a Sedano -Gredilla, Moradillo, Nocedo, Huidobro, Valdelateja, San Felices, Sargentes, Covanera, Tubilla del Agua, Masa- ha permitido documentar una fuerte desproporción en el número de grandes y pequeños monumentos, apreciándose densidades mucho más importantes de estos últimos y un mayor aislamiento de aquellos, lo

T. P., 57, n. $^{\circ} 2,2000$ 


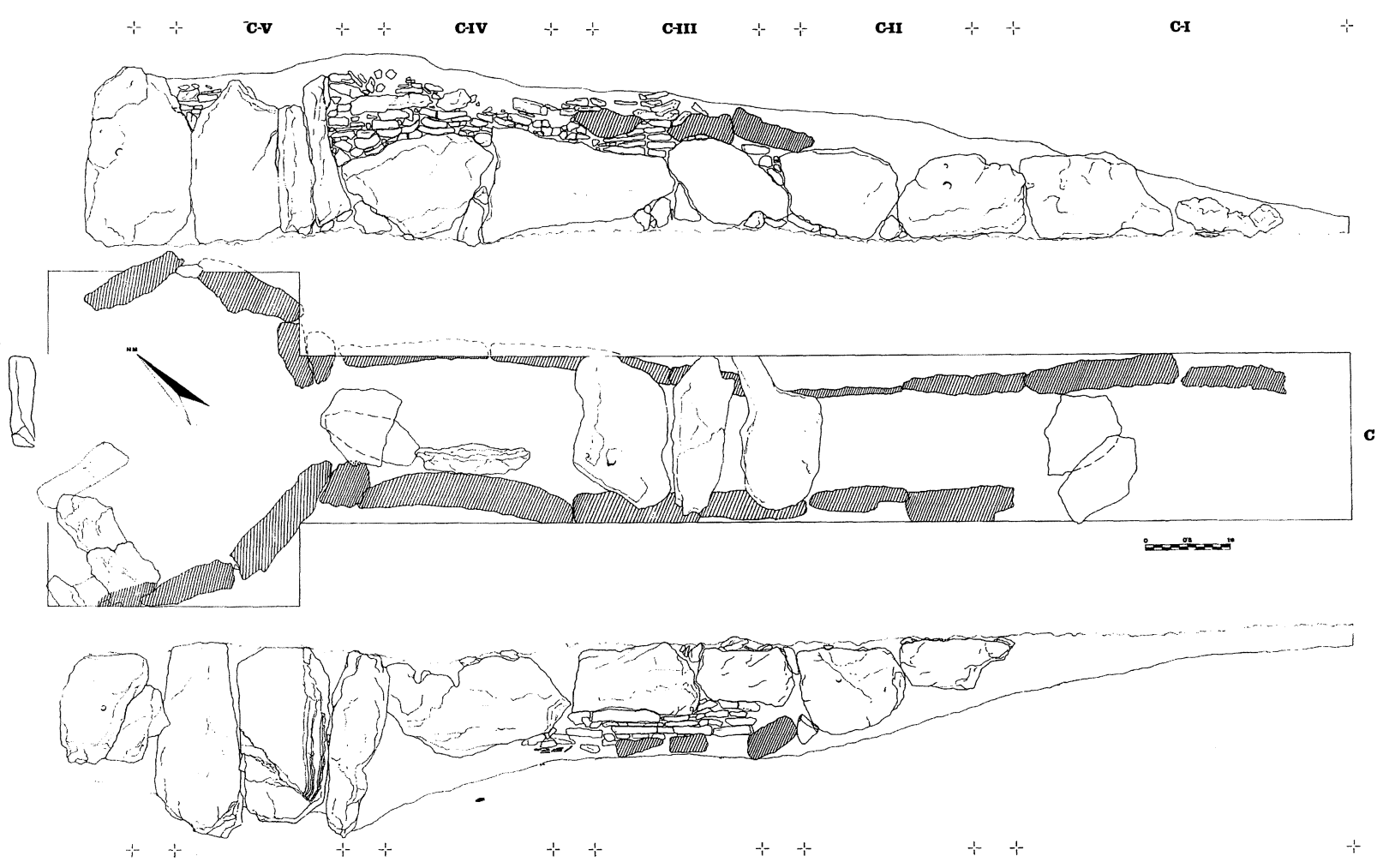

Fig. 3. Planta y alzados del sepulcro de corredor de Las Arnillas, Moradillo de Sedano (Burgos).

cual, habida cuenta la distinta cronología de unos y otros, confirmada por la segregación de los ajuares, nos permite apostar por una cierta interdependencia entre la progresiva monumentalidad de las tumbas y un creciente proceso de agregación de los pequeños grupos sociales beneficiarios de los numerosos sepulcros del momento inicial (Delibes y Rojo, 1998).

Al contrario que en otras áreas de la Meseta, en las que unos suelos excesivamente ácidos no permiten la supervivencia de material arqueológico alguno de origen orgánico, los dólmenes de La Lora aportan notables osarios, ilustrativos de la finalidad funeraria de los monumentos y de su condición de enterramientos colectivos. El número de individuos inhumados, muy distinto en unas tumbas y en otras y mayor por lo general en los grandes sepulcros de corredor, no alcanza por muy poco el medio centenar en Las Arnillas donde, además, existe la oportunidad de comprobar cómo el reclutamiento del calavernario, depositado a lo largo de un periodo de tiempo considerable, fué selectivo: se excluyó de él de forma bastante sistemática a los niños (tal vez no merecían tales honores hasta alcanzar cierta edad) y la representación de las mujeres en la tumba es dos tercios inferior a la de los varones, de donde se desprende, frente a la idea tradicional de que el dolmen fué la sepultura de todos y a todos igualaba en la muerte, que sólo una parte de los miembros del grupo tuvieron derecho a enterrarse en ella (Delibes, 1995).

El aspecto de absoluto revuelto que muestran los osarios y que tan complicada hace su excavación no impide reconocer que en su momento los cadáveres fueron depositados con todos sus miembros en perfecta conexión anatómica. Ello descarta que, al menos como norma, los dólmenes fueran lugares de enterramiento secundario y confiere sustento -máxime pensando en esa condición diacrónica y progresiva del depósito- a la sospecha de que las ofrendas recuperadas en su interior fueron de carácter individual: en los enterramientos más antiguos, triángulos y trapecios de sílex, más o menos microlíticos, a más de espátulas de hueso tipo San Martín-El Miradero; en los más modernos, puntas de flecha romboidales o pedunculadas con retoque plano; en la generalidad, láminas-cuchillo, hachas pulimentadas y una pléyade de cuentas de collar. Sólo en casos contados, vasijas cerámicas (Delibes y Rojo, 1992)(Fig. 4). 

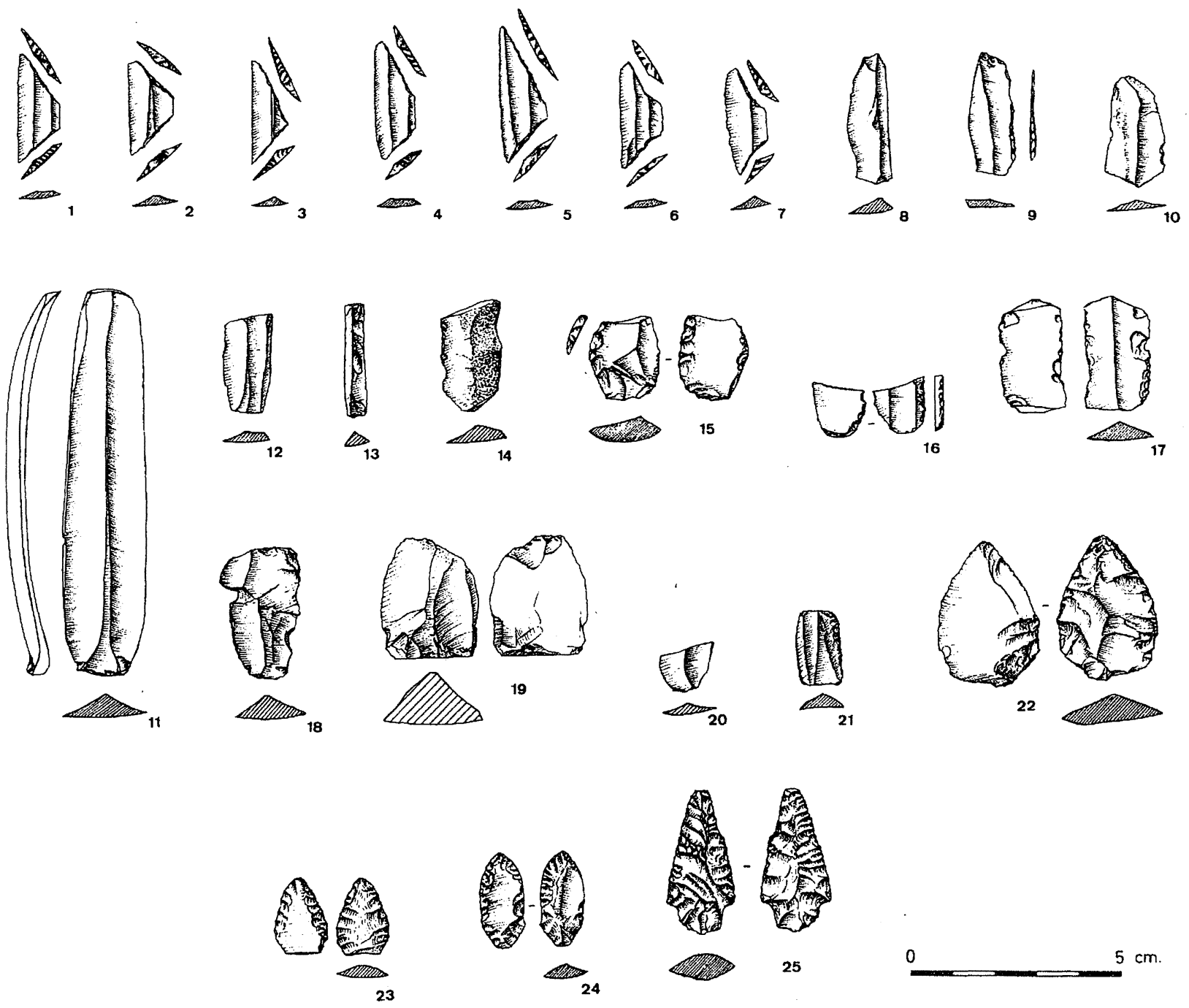

0 $5 \mathrm{~cm}$.

Fig. 4. Elementos de ajuar representativos de los megalitos de la Lora burgalesa: 1-7 geométricos; 9-21 láminas o fragmentos; restantes, puntas.

Avanzar más en el intento de reconstruir el ceremonial funerario que regía en los megalitos de La Lora es, sin duda, empresa difícil aunque factible a través de otros detalles: la aplicación de ocres a los cadáveres (Las Arnillas); la existencia de puntos de fuego en las cámaras (¿sólo para la iluminación?); las concentraciones de cráneos -como la atestiguada en el acceso de Las Arnillas-formando auténticos nidos bien segregados de los carneros u osarios generales; el reconocimiento no excepcional de trepanaciones o la identificación, de nuevo en Las Arnillas, de un soberbio puñal sobre fémur humano que no cabe sino considerar reliquia relacionada con alguna suerte de culto a los antepasados (Delibes et alii, 1986). Inclusive las pocas eviden- cias de arte megalítico captadas en los sepulcros de este espacio -las cazoletas y los esquemáticos antropomorfos, pintados, de El Moreco o el pseudoarte ("arte natural") de las losas del pasillo de Las Arnillas (Delibes y Moreno, 2000)- hubieron de tener significado propio en el marco de ese ritual del que apenas somos capaces de reconocer las líneas maestras o los trazos más gruesos de su complejo diseño (Delibes y Rojo, 1989).

Cerca de una veintena de dataciones de C-14 sirven de apoyatura a las consideraciones cronológicas y evolutivas sobre este foco megalítico. Las fechas absolutas de un túmulo predolménico (El Rebolledo) y de los megalitos simples de tipo Fuente Pecina II vienen a situar el punto de partida de 
esta arquitectura funeraria monumental hacia mediados del IV milenio a.C. (mitad delV milenio cal BC). La plenitud de los sepulcros de corredor, a juzgar por los datos de La Cabaña, El Moreco o Las Arnillas, tuvo lugar en torno al año 3000 a.C. y la clausura de los mismos - en El Moreco plasmada en un bloqueo concienzudo y sistemático del pasillohubo de acaecer sobre la mitad del III milenio pues el osario del sepulcro gemelo de Las Arnillas aun estaba abierto poco antes del 2600 (Delibes y Rojo, 1997).

Nada de ello, sin embargo, impide reconocer que, con posterioridad, los dólmenes recuperaron parte del protagonismo perdido. Elementos significativos de ajuar campaniforme (una punta Palmela en La Mina, botones perforados en V en Las Arnillas), asociados en ambos casos a bien típicas cerámicas incisas de tipo Ciempozuelos (Fig. 5), demuestran que los personajes más destacados socialmente de la plenitud de la Edad del Cobre, como los de otros muchos espacios peninsulares por esta misma época, sintieron también en La Lora burgalesa la necesidad de recuperar la tumba atávica para mejor reivindicar su vinculación al linaje divino de los antepasados, por más que algunos de sus contemporáneos dieran cuenta de su distinción construyendo sepulturas de nueva planta, aunque asímismo tumulares, como son en esta zona las de Tablada de Rudrón y el Paso de La Loba (Campillo, 1985; Rojo, 1989). Algunas ofrendas de época incluso más avanzada -cerámicas lisas de fondo plano de San Quirce, un vasito inciso de tipo Arbolí en Ciella o una fíbula de codo en Las Arnillas-, por desgracia mal contextualizados, dan pie a sospechar una situación análoga en la Edad del Bronce, aunque en este caso, como en el de los materiales de época histórica más avanzada (romanos, medievales, modernos y contemporáneos), no puede descartarse la posibilidad de que se trate de simples pérdidas sufridas por antiguos buscadores de tesoros en cuya memoria sobrevivía la imagen mítica de aquellos cada vez más incomprensibles monumentos.

El proyecto aplicado durante años al estudio de los dólmenes de La Lora no ha vivido en ningún momento de espaldas a la necesidad de completar la visión de la época a la que tales monumentos corresponden con datos sobre el modelo de poblamiento, las actividades subsistenciales o las formas de organización social de las comunidades usuarias. Por más que los documentos más sobresalientes del registro arqueológico fueran las tumbas, no
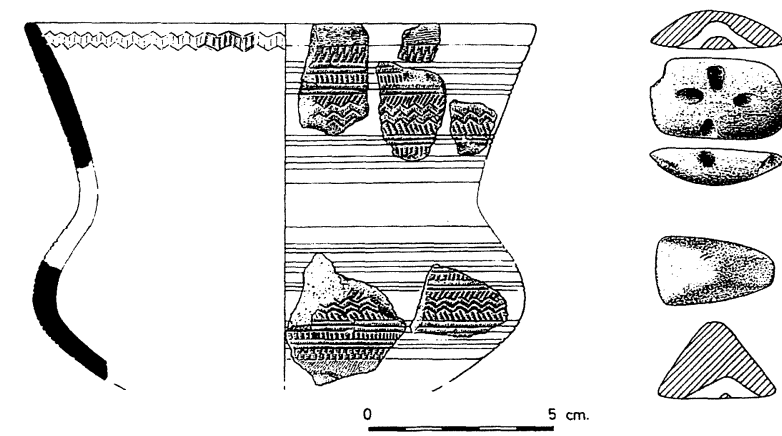

Fig. 5. Vaso campaniforme y botones de hueso perforados en «V» de Las Arnillas, Moradillo de Sedano (Burgos).

podía pasarse de puntillas sobre esos otros aspectos más difíciles de captar reproduciendo una vez más la imagen fantasmal de tumbas sin vivos que, tan gráfica como justificadamente, dieron pié a Fleming a hablar de una "civilización de muertos" (Delibes, 1991). El empeño por superar ese absurdo ha sido considerable -mucha prospección sistemática y dirigida y mucha encuesta en el medio rural para dar con los hábitats de la población megalítica- pero, siendo sinceros, los resultados no han estado a la altura del esfuerzo realizado. Nos queda una pequeña duda sobre si aquellas comunidades no pudieron morar -como las históricas- en los valles profundos y estrechos de la red del Ebro-Rudrón y es duda difícil de despejar por cuanto el fondo de los mismos presenta hoy un espeso manto de arcillas y clastos de aporte relativamente reciente (en el barrio de Lagos, aguas arriba de Sedano, en el curso del Moradillo, los sondeos para cimentar un moderno edificio alcanzaron, tras más de una decena de metros de excavación, un nivel de turba rico en maderas que se presume tardiglaciar), que enmascararía eficazmente cualquier resto anterior. En todo caso, no es esta nuestra hipótesis favorita por cuanto el valle, con un terrazgo ínfimo (hoy una estrechísima tira de huertas) e incómodo (suelos pesados, amenazados de forma permanente por la invasión arbórea), no parece el medio más adecuado para satisfacer las necesidades de unas comunidades agrícolas embrionarias. Por ello nos decantamos más bien por la idea de que estas escogieron para el asentamiento los valles altos y los bordes de los páramos con modestos puntos de agua, allí donde precisamente encontramos documentos -restos de industrias laminares, con geométricos de doble bisel y alguna punta romboidal; cerámicas muy toscas; morteros y molinos de mano, algún hacha puli- 


\begin{tabular}{|l|c|c|l|c|}
\hline & Cod. Lab. & Fecha BP & \multicolumn{1}{|c|}{ Tipo de tumba } & Procedencia \\
\hline Fuentepecina 1 & GrN 16.073 & $5270 \pm 140$ & Dolmen simple (?) & Nivel 3 \\
\hline Fuentepecina 2 & GrN 18.667 & $5170 \pm 100$ & Dolmen simple & Nivel 6 \\
\hline Fuentepecina 2 & GrN 18.668 & $8260 \pm 50$ & Dolmen simple & Nivel 1/2 \\
\hline Fuentepecina 2 & GrN 18.669 & $5375 \pm 45$ & Dolmen simple & Nivel 6 \\
\hline Rebolledo & GrN 19.567 & $5075 \pm 40$ & Túmulo no megalítico & Nivel 3 \\
\hline Rebolledo & GrN 19.568 & $6775 \pm 30$ & Túmulo no megalítico & Nivel 1/2 \\
\hline Rebolledo & GrN 19.569 & $5305 \pm 30$ & Túmulo no megalítico & Nivel 6 \\
\hline Las Arnillas & GrN 12.124 & $4575 \pm 40$ & Sepulcro de corredor & Nivel 6 \\
\hline Las Arnillas & GrN 18.671 & $4720 \pm 150$ & Sepulcro de corredor & Nivel 3 \\
\hline El Moreco & GrN 12.994 & $5150 \pm 60$ & Sepulcro de corredor & Nivel 3 \\
\hline La Cabaña & GrN 18.670 & $5240 \pm 65$ & Sepulcro de corredor & Nivel 3 \\
\hline San Quirce & GrN 14.492 & $1810 \pm 110$ & Sepulcro de corredor corto & Nivel 3 \\
\hline San Quirce & GrN 14.493 & $3770 \pm 190$ & Sepulcro de corredor corto & Nivel 6 \\
\hline Valdemuriel & GrN 14.028 & $5670 \pm 110$ & Sepulcro de corredor corto & Nivel 3 \\
\hline Valdemuriel & GrN 14.494 & $6565 \pm 45$ & Sepulcro de corredor corto & Nivel 2 \\
\hline Ciella & GrN 12.121 & $5290 \pm 40$ & Sepulcro de corredor corto & Nivel 3 \\
\hline La Mina & GrN 14.951 & $5100 \pm 170$ & Sepulcro de corredor corto & Nivel 3 \\
\hline
\end{tabular}

Tab. 1 Dataciones C-14 de distintos sepulcros dolménicos del área de Sedano (Burgos).

mentada...- atribuibles a este momento final del Neolítico (Tab. 1). Tales sitios son Canalejas, inmediato a Fuente Pecina, Las Casarinas, cerca de Ciella o La Nava Alta de Nocedo, a no demasiada distancia de El Moreco y, a tenor de la escasa entidad de sus estructuras, se diría corresponden a ocupaciones no largas, si bien el hecho -acreditado por análisis polínicos del suelo infratumular de El Moreco (2)- de que los campos de cultivo de cereal se sitúen asimismo en sus inmediaciones hace improbable que la totalidad del grupo humano se alejase resueltamente del sitio o de su entorno durante los 10 meses que en esta tierra dura el ciclo agrícola de secano (de octubre a no antes de agosto). No son pocos los argumentos, en fin, para sospechar que el territorio económico por excelencia del hombre neolítico sedanés fue esa paramera adusta y pobre, ya por entonces ( $¿$ de resultas de la propia actividad humana?) despojada básicamente de una cobertera arbórea importante (Muñoz Sobrino et alii, 1996), en la que, no obstante, todavía encuentran hoy alimento suficiente los rebaños de ovicaprinos.

(2) P. López (1988): Estudio palinológico del suelo infratumular del sepulcro de El Moreco, en Huidobro (Burgos). Madrid. Mecanografiado.

\section{TRABAJOS DE RECUPERACIÓN, CONSOLIDACIÓN Y ADECUACIÓN EN LOS TÚMULOS MEGALÍTICOS DE LA LORA}

Por diversas razones, todas ellas fáciles de comprender, bastantes de los monumentos a presentar al público se hallaban en el momento de decidir su recuperación en una situación muy precaria. Ello era, en gran medida, debido al expolio brutal al que habían sido sometidos a lo largo del periodo histórico (especialmente visible en El Moreco), del que da cuenta muy expresivamente el topónimo de uno de los yacimientos: La Mina. En otros casos puede sospecharse que parte de dicho deterioro fuera consecuencia de demoliciones deliberadas, como las que han llegado a acreditarse en dólmenes de áreas próximas, para sancionar la clausura o condenación de las tumbas en época todavía prehistórica (López Calle e Ilarraza, 1997). En los tramos iniciales, inmediatos a la cámara, de los corredores de Las Arnillas y Porquera de Butrón existe constancia, al contrario, del desplome, seguramente accidental de algún dintel de cubierta cuando los monumentos se hallaban aún en pleno uso, como se desprende de la inclusión de dichas cubiertas en los niveles funerarios correspondientes (Delibes et alii, 1986).Y, por qué negarlo, la propia excavación arqueológica, que

T. P., 57, n. ${ }^{\circ} 2,2000$ 
en un primer momento contribuye a una presentación limpia, ordenada y más o menos ennoblecida de las arquitecturas, acaba actuando $-\mathrm{y}$ sus efectos desoladores tardan poco más de un invierno en hacerse notar-como un nuevo factor si no de destrucción sí de desestabilización de los yacimientos, como hubimos de reconocer tras bien merecidas denuncias de la prensa provincial sobre la penosa situación en que los arqueólogos dejabamos, después de su disección, la antes airosa mole tumular de El Moreco.

La selección de los monumentos a incluir en el Itinerario, de entre la docena de los excavados, estuvo condicionada en parte, como dijimos ya, por su accesibilidad -la decisión de desestimar Fuente Pecina responde a este criterio, bien a nuestro pesar dada la personalidad arquitectónica de sus túmulos-, pero tambien por el grado de arrasamiento de las construcciones. Los dólmenes de San Quirce, Ciella o La Mina mostraban tan abrumadora devastación que se optó por refosilizarlos bajo improvisadas moles neotumulares, devolviéndoles en lo posible su sobrio aspecto original. En los demás casos, de cara a la revitalización, esto es a hacerlos comprensibles estructuralmente y a frenar su deterioro, se planearon labores de consolidación, de restauración e incluso de recuperación, aunque siempre huyendo de falsificar y de los excesos de la reinvención ya que, como ha señalado Represa, arquitecto director de dichos trabajos, la filosofía seguida evitó la tentación de cualquier reconstrucción insuficientemente documentada y sin el necesario apoyo científico por ser algo censurable como postura ideológica en la restauración. Lejos, pues, del "síndrome Disneylandia" o de la idea postmoderna, ingenua o perversa, de que el Patrimonio no se hereda sino que se crea (Junyent, 1999: 21), no ha habido más añadidos que los obligados para hacer inteligible la forma monumental y éstos siempre supeditados a una documentación fidedigna. Los monumentos apenas si han sufrido una mínima recreación, nada agresiva, no existiendo el menor problema de reversibilidad en lo acometido.

La intervención en las estructuras propiamente megalíticas, más allá del apuntalamiento o de la opción de enderezar alguno de los ortostatos a fin de devolverles su verticalidad primigenia, se ha orientado fundamentalmente a la restitución de las losas imprescindibles (sucede en Las Arnillas, El Moreco, Porquera o La Cabaña) para garantizar la estabilidad del conjunto y, no menos importante, para conseguir una impresión de ambiente cerrado, en el caso de las cámaras, y de dromos, de lugar de paso, en el de los corredores. En todo momento se ha huido del empleo de losas labradas artificialmente, recurriéndose a bloques naturales, de calizas locales tableadas, como las aprovechadas en su día por los constructores megalíticos, con lo que se logra cierta homogeneidad para el conjunto de la construcción que, en modo alguno, puede provocar en el espectador confusión entre lo auténtico y lo añadido por cuanto los nuevos elementos portan como distintivo un contraste metálico. Nunca las nuevas losas hincadas, en todo caso, se han colocado discrecionalmente, invocando por ejemplo razones de simetría, sino de acuerdo con la posición -y respetando las dimensiones- de las originales, cuyas improntas excavadas en el suelo del páramo no ha sido difícil, en la mayor parte de los casos, distinguir. Excepcionalmente, cuando los nuevos ortostatos, por problemas de falta de regularidad, no ajustan con precisión con sus vecinos, han podido presentarse (El Moreco) huecos o lagunas entre los mismos que podrían zapar los túmulos y producir derrames de sus tierras en el interior de los monumentos; es problema tambien advertido en la arquitectura original de Las Arnillas o de La Cabaña y que, como entonces en ellos, tambien se ha solucionado recurriendo a labores menores -auténticos parches- de mampostería en seco o de tapas de cara plana.

La sumisión del proyecto a la información arqueológica ha llevado, en perfecta sintonía con la idea de una recuperación blanda o poco agresiva, a no actuar en las cubiertas camerales. Ya se ha señalado la importancia que damos a que el visitante participe de la sensación de acceder, llegado a la cámara del megalito, a un recinto cerrado: es el espacio sagrado del interior del monumento, frente al exterior profano. Y nada es más evidente que tal sensación se habría conseguido de forma mucho más eficaz introduciéndole en un recinto techado como no tenemos la menor duda fué en su tiempo la susodicha cámara. El desconocimiento de cómo fué, en rigor, tal cubierta y la circunstancia de que no hayan sobrevivido, en ninguno de los monumentos excavados en la zona, evidencias indirectas más o menos concluyentes de su sistema constructivo han obligado a prescindir de ella, al precio de producir un problema de encuentro entre las partes cimeras de las paredes megalíticas y las cotas más altas -a un nivel superior-del túmulo envolvente. Un problema resuelto por medio de un plano de derrame de este último en cono o caldera volcánica 


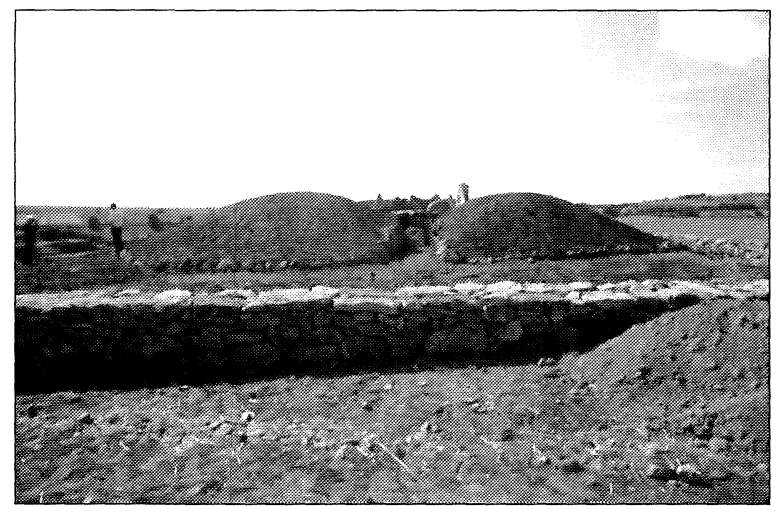

Lám. I. Aspecto del túmulo de La Cotorrita (Porquera de Butrón, Burgos), tras su recuperación.

que, además de inducir al espectador a la sospecha de que alguna vez hubo de haber allí la cubierta que hoy no existe, le hace partícipe también de la importancia y del sentido de la estructura tumular. No se ha planteado ese mismo problema con las tapaderas del corredor, que se saben planas por los hallazgos in situ de, sobre todo, Las Arnillas y La Cabaña, lo que animó al restaurador a restituir las caidas e incluso a añadir algunas otras no debidamente documentadas por entender que con tan recatada audacia se produciría más eficazmente en el visitante la sensación de transitar por un espacio restringido.

La recuperación de los túmulos fué, sin duda, otra de las tareas claves en el ejercicio de la restauración. Rebajados en algunos casos (Porquera de Butrón)(Lám. I) a resultas de la erosión y recortados irregularmente sus perímetros en otros $(\mathrm{La}$ Cabaña) como consecuencia de su ubicación en áreas de cultivo, sólo en Las Arnillas y Valdemuriel era evidente que la cota cimera de sus tierras estuvo en origen, por lo menos, al ras del extremo superior de los ortostatos de las cámaras (siempre los más altos de toda la construcción), mientras que en El Moreco, inclusive, se hacía evidente que la altura del túmulo había superado claramente a la de tales bloques, como prueba incontestable de que toda la estructura megalítica permaneció primitivamente sepultada bajo las tierras de aquel. De ahí la decisión de devolver su porte inicial a aquellos túmulos que lo habían perdido, máxime intuyendo que con ello -cual hubo de suceder en la prehistoria- los monumentos multiplican su presencia, adquieren mayor protagonismo en el espacio y aumentan la atracción en el espectador. Este, por tanto, al aproximarse al yacimiento (p.e. de Las Arnillas) no percibe más que un cuerpo cónico de tierra y sólo cuan- do gira en torno al mismo será capaz de descubrir la portilla o gatera de acceso al corredor, con lo que, todavía sin penetrar en ella, le será dado captar que existe un monumento interior por descubrir. En todo caso, el mencionado recrecimiento de los túmulos ha tratado de ser respetuoso con los procedimientos constructivos primigenios y no sólo por el prurito de ser fieles a los modelos. Nos referimos a que, como ya se ha anotado en el epígrafe inicial, los túmulos han contado sistemáticamente con corazas de piedra más o menos epidérmicas, hoy directamente bajo el tapiz vegetal o envueltas con él, las cuales se han reproducido con toda fidelidad en las reconstrucciones, bien es cierto que ello, más que nada, por saber que las calizas que las componen tienen una gran capacidad de absorber humedad y de retenerla, lo que propicia la formación y supervivencia de una cubierta de plantas rastreras (p.e. la gayuba o hierba viborera) que, insensibles al agostamiento general que sufre la paramera en pleno verano, ennoblecen con su verde brillante el aspecto de los montículos y acrecientan su visibilidad.

A tenor de los resultados de las excavaciones, no parece que haya habido pavimentación o suelo artificial alguno dentro de los monumentos; debieron ser suficientes, pues, los naturales del páramo, constituidos por una estrecha capa de arcillas resultantes de la descomposición del omnipresente sustrato calizo. Sin embargo, en la recuperación de las ruinas se adoptó la medida de crear soleras nuevas, de una coloración bien distinta de la de los alzados de piedra, como procedimiento para subrayar la, por lo general muy regular, planta geométrica de las construcciones. Se trata de suelos de arcillas compactadas mecánicamente y estabilizadas con silicatos de etilo que, si bien en épocas lluviosas muestran un elevado grado de plasticidad, en la larga etapa seca deparan superficies firmes y lisas, limpias y cómodas para el tránsito. Una licencia en la restauración, sin duda, por lo que supone de crear una realidad que no llegó a existir, pero casi irrelevante al lado de la decisión de individualizar cada túmulo dentro de una construcción no menos inventada. Esta sí puede considerarse una medida discutible en el marco de la general filosofía restauradora; no menos polémica por lo que representa de menoscabo de la visión poetizada de una ruina arqueológica. Como contrapunto, sin embargo, el discreto vallado de piedra en seco es firme y disuasoria protección ante las roturaciones agrícolas abusivas o frente a los daños potenciales de un ga-

T. P., 57, n. $^{\circ} 2,2000$ 
nado que, en esta zona, se desenvuelve comunmente en semilibertad (Lám. II). La determinación de recurrir a estos recintos responde básicamente, no obstante, a otra razón: contribuye a significar la presencia de los monumentos y, sin apenas obstaculizar su percepción, pues hablamos de muretes muy bajos, que no superan los $80 \mathrm{~cm}$, se reducen a una línea horizontal, de muy escasa entidad, sobre la que, entonces sí, con esa escala, los túmulos están en condiciones de transmitir su verdadera dimensión. Constituyen, por tanto, un muy discreto y útil marco de referencia, casi una escala; que resalta ese carácter de hito paisajístico y símbolo espacial que desde el mismo momento de su construcción creemos acompañó a estos enterramientos.

\section{LOS RECURSOS DIDÁCTICOS PARA LA VISITA}

Si el núcleo del Itinerario son, evidentemente, los cinco monumentos megalíticos recuperados, su simple exhibición no logrará aleccionar con solvencia al visitante más profano sobre las circunstancias históricas, sociales y económicas en que tales construcciones se desenvolvieron. Sencillamente los dólmenes, pese a su mayor o menor vistosidad, no se explican por sí mismos, de ahí la lógica preocupación de los promotores de la idea del Itinerario por dotar a este de una infraestructura informativa que contribuya a divulgar entre el público los mensajes de que son portadores y facilite su correcta interpretación (Hernández Cardona, 1998). Esta información se sitúa en niveles distintos: la hay que no es mucho más que una señalización de tráfico para facilitar el acceso a los yacimientos; se cuenta también con el auxilio de una guía de visita editada por la Junta de Castilla y León (Delibes et alii, 1993); en cada dolmen se ha instalado, además, un discreto atril con unos dibujos y un pequeño texto alusivo a algún aspecto relevante del mismo; y, por último, la oferta didáctica se completa con unAula Arqueológica -en el pueblo de Sedano-en la que, a través de paneles, de maquetas y de la recreación a tamaño natural de una cámara megalítica con su correspondiente osario, se proyecta una imagen accesible y sugerente de lo que fue en la comarca el fenómeno del megalitismo. Tanto los paneles informativos como el aula han sido diseñados, tomando como base el conocimiento derivado de la investigación y restauración, por el gabinete arqueológico Arquetipo.

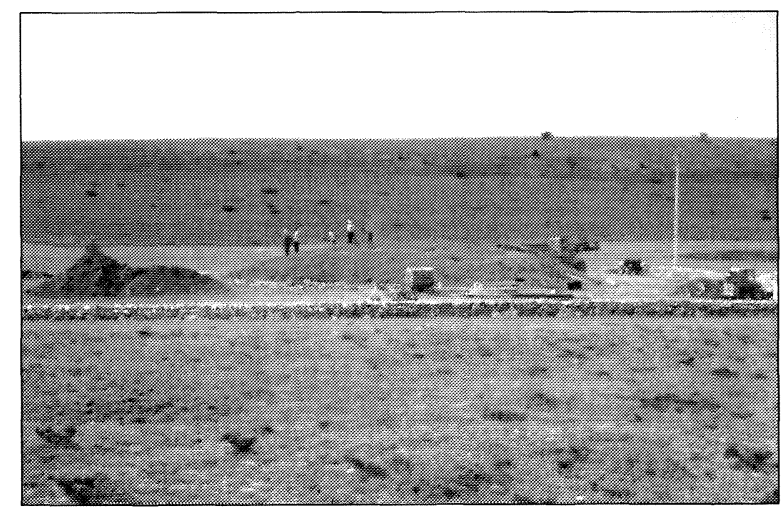

Lam. II.Trabajos de recuperación y restitución en el túmulo de El Moreco (Huidobro, Burgos). En primer término, la tapia de demarcación del espacio acotado.

Los carteles generales de la ruta, de gran tamaño, con información básica sobre el contenido de la visita y sobre.la dimensión histórica de los dólmenes, y con un limpio y sencillo mapa en el que se localizan los cinco monumentos visitables, mas el aula, en relación con la red principal de carreteras, son sólo dos, ubicados en puntos estratégicos: San Felices de Rudrón, en la muy transitada carretera nacional 623, Madrid-Santander, desde donde se accede directamente a La Cabaña de Sargentes, y Sedano, en tanto reclamo para el aula instalada en los locales de su ayuntamiento y punto de partida razonable para iniciar el circuito hacia los páramos de Gredilla y LosAltos-Dobro, descender a Porquera de Ebro y, Rudrón arriba, acceder al ya mencionado pueblo de San Felices y a Tubilla del Agua.

Quien, con el ánimo de completar el circuito, desee una más prolija información sobre los monumentos que el de las postas previstas o, inclusive, no descarte, siendo aficionado a la excursión a pié, visitar los dólmenes no comprendidos en el Itinerario (en el caso de La Nava Negra o de la necrópolis de Fuente Pecina sóló por razones de su difícil acceso en automovil), encontrará el necesario auxilio para hacerlo en la Guía a la que nos hemos referido más arriba, con un texto general sobre el fenómeno megalítico en La Lora, con información sobre cada yacimiento - poniendo especial cuidado en señalar el camino más sencillo para llegar a él-y con un mapa de cierto detalle en el que figura la localización de los sitios arqueológicos de mayor interés. En los monumentos del Itinerario, empero, el visitante dispondrá de unos atriles que le facilitarán un muy tenue fondo de información básica, sin por ello dejar de aludir a algún aspecto particular del 
dolmen contemplado. La determinación de qué es lo que habían de explicar estos atriles no estuvo libre de discusión, al dudarse de si procedía un discurso generalista sobre el megalitismo, el mismo prácticamente para todos ellos -coordenadas cronológicas, contexto socioeconómico y tecnológico de las construcciones, ritual y ofrendas, etc-, que cumpliese con el objetivo de aleccionar de forma más o menos satisfactoria a los visitantes de uno solo, cualquiera, de los sitios, u otro más particular que ilustrase específicamente sobre algún aspecto determinado del yacimiento, en evitación de repetir los mismos o muy parecidos mensajes, lo que no hubiera dejado de ser decepcionante para quienes completaran la totalidad de la ruta.

Prevaleció, finalmente, la segunda opción y así, sin dejar de atender siempre a un mínimo de contextualización (los dólmenes son tumbas prehistóricas, del Neolítico, con una antigüedad de cerca de 6000 años, etc), se particulariza en cada caso: en Porquera, donde se exhumó en su día un notable osario, se insiste sobre todo en que aquellos monumentos fueron lugares de enterramiento colectivo diacrónico; en El Moreco, aprovechando el colosalismo de la construcción, se incide en los aspectos estructurales y arquitectónicos de la tumba para dar traslado al público del sentido de términos tales como cámara, corredor, ortostatos o túmulo; Las Arnillas, con su sobresaliente presencia espacial y enorme campo de visibilidad circundante, dará pie a reflexiones sobre el mensaje territorial de los dólmenes o, utilizando palabras de Rojo (1990), a la exégesis de sus emplazamientos; en el panel de La Cabaña, aprovechando la existencia de un conjunto de lastras naturales, análogas a las del dolmen, en la inmediata cantera del arroyo del Navazal, va a especularse, tomando como base la conocida experiencia de los dólmenes de Bougon (Mohen, 1980), sobre la precariedad y los costes de la "ingeniería megalítica", y en Valdemuriel se partirá del primitivismo y antigüedad de su peculiar arquitectura (un sepulcro de corredor embrionario, de mediados del IV milenio) para reflexionar sobre la profundidad de la trayectoria dolménica de la región y la evolución estructural de los monumentos.

El Aula Arqueológica, ubicada como hemos adelantado en el edificio del Ayuntamiento de Sedano y diseñada porArquetipo (3), se plantea como objetivo principal "ofrecer una visión general del

(3) Proyecto de Aula Arqueológica. Dólmenes de La Lora burgalesa. Soria, 1998, mecanografiado. mundo megalítico, vinculándolo al grupo humano que lo produce, a su modo de vida y a la relación económica que este ha establecido con el medio", siendo mérito de la misma despojar a los datos científicos de su proverbial gravedad para una menos costosa (y, en lo posible, lúdica) comprensión por parte del público (Morales Miranda, 1998). Puede ser el colofón y el punto de partida del Itinerario, recomendándose más bien lo segundo, esto es su conversión en un recurso pedagógico para crear la máxima expectación -siempre desde el conocimiento- de cara a la posterior contemplación de los verdaderos monumentos. Se distribuye en dos salas articuladas por un patio, concentrándose en la mayor (aún así, pequeña en exceso) dos paneles, una vitrina y una maqueta interactiva, mientras que la segunda ha sido convertida en el misterioso interior de un sepulcro megalítico. Los paneles de la primera, de gran tamaño, cumplen también aquí una finalidad informativa, introducen al visitante en el tema, en uno de los casos recogiendo ideas muy básicas sobre qué son, cómo se construyen y de cuándo datan los dólmenes y en el otro -convertido en un pintoresco y atractivo fresco- recreando muy diferentes escenas de la vida cotidiana de aquellos hombres: se les presenta, inevitablemente, como constructores de los megalitos, pero también como cultivadores de cereal, como pastores, como miembros de una comunidad que vive en aduares o campamentos de poca monta y cuyos quehaceres diarios son los propios de un colectivo que practica una economía de subsistencia: majan cereales, destazan y preparan el botín cinegético, etc. Una mesa-vitrina acoplada a su base, con reproducciones a escala 1:1 de molinos barquiformes, de puntas de flecha engastadas, de burdas cerámicas modeladas a mano, de hachas pulimentadas con sus mangos o de hoces de madera con la consabida incrustación de dientes de piedra, completa eficazmente aquella imagen.

La maqueta instalada en uno de los extremos de la primera sala -un monumento cuya cubierta se levanta para conocer el "tesoro" arqueológico que encierra: cadáveres y ajuares, básicamente- nos aproxima a lo que será la sala 2, convertida en la cámara de un dolmen a tamaño natural. Para ello el interior, cuadrado, de la pieza ha sido reconvertido, mediante seis ortostatos de fibra de vidrio, en una cámara casi circular, con suelo de tierra y techumbre lígnea (la intuida para estas construcciones), a la que se accede por un pasillo, obligatoriamente corto por las dimensiones del local, que recuerda 
también el de los sepulcros de corredor. La disposición de la estructura genera curiosidad, sin duda, e invita a penetrar (¡casi de uno en uno!) al locus principal del monumento, máxime cuando fuera, en el patio, dos maniquíes se sirven de parihuelas para trasladar hacia allí un cadáver, explicitando con rotundidad el significado del lugar. Ya dentro, la imagen del calavernario, abigarrado y agobiante, con sus elementos de ajuar (hachas, láminas, geométricos y puntas de flecha de sílex o algún útil de hueso), se hará aún más solemne con una iluminación adecuada y con una voz en off que ofrece pormenores de la ceremonia fúnebre sin eludir, por ejemplo, el sentido de un tercer maniquí, de forexpán, que espolvorea el mágico ocre sobre los enterramientos. El conjunto, sin duda, cumple con el deseo de enseñar lúdicamente aunque, a nuestro entender, tiene un peso excesivo en un Aula que por ello parece llamada antes alentertainment que a una labor más explícitamente formativa.

\section{PERSPECTIVAS DEL PROYECTO}

A estas alturas de la iniciativa y ya sin posible retorno -el Itinerario es una realidad insoslayable, en la que se ha hecho una importante inversión económica encaminada a la conservación y mis en valeur de los dólmenes regionales- no dejan de asaltarnos ciertas dudas razonables sobre su futuro. En todo caso se trata de dudas relacionadas antes con factores de tipo infraestructural que con el interés intrínseco de los megalitos pues éste, vista la entusiasta acogida que se les ha dispensado antes de su recuperación y de ser difundida su existencia, se diría incuestionable. Pero no por ello pueden pasarse por alto determinadas circunstancias que, pese al interés de la iniciativa, podrían condicionar el éxito de la misma.

A su favor juega, evidentemente, el hecho de que los nuevos incentivos arqueológicos vengan a sumarse a otros que han convertido en los últimos lustros la zona del Noroeste de la provincia de Burgos en un polo de indudable atracción turística. Un bello románico popular, que encuentra sus mejores exponentes en las iglesiucas de Moradillo de Sedano o Gredilla y, sobre todo, un patrimonio natural privilegiado, con los espectaculares cañones del Ebro y del Rudrón, con los recoletos hayedos de Huidobro o con las surgencias del Pozo Azul, en Covanera, como principales señuelos, servirán, así, de complemento (o viceversa) a la iniciativa del turismo arqueológico, lo cual no es poco importante ante el escepticismo de que ésta, por sí sóla, pudiera llegar a ser el elemento dinamizador necesario para el desarrollo de una comarca tan deprimida como la nuestra.

En el extremo opuesto, empero, operan otros factores menos favorables y que no dejan de proyectar alguna incertidumbre sobre el futuro del Itinerario. Tal vez, en nuestra opinión, el más preocupante radique en la descentralización de la visita, en el hecho de que esta se dirija no a uno sino a varios yacimientos separados entre sí por varios kilómetros. Por de pronto, ello ha impedido que se concentren los esfuerzos de la iniciativa en un único escenario, lo que supone diluir un tanto el efecto de ese primer impacto visual sobre los documentos a disfrutar que tan importante suele ser para el éxito de esta clase de empresas. Por razones obvias, sólo existe la posibilidad de contemplar un dolmen en cada sitio y, en cualquiera de los casos, lejos del lugar donde mejor se explica lo que son. ElAula, en efecto, tan importante para comprender la totalidad del mensaje del Itinerario, no deja de representar un centro informativo a distancia del que el visitante no dispone en cada yacimiento. Empaparse en el susodicho mensaje será posible, pues, sólo para aquellos que deliberadamente hayan decidido efectuar la totalidad del circuito, no para quien tropiece por azar con uno cualquiera de los megalitos de la ruta.

Esta misma descentralización de los monumentos que se exhiben también habrá de suponer un obstáculo para lograr un control permanente sobre ellos e, indirectamente, para garantizar su conservación. Los dólmenes están expuestos a los rigores de una climatología adversa, sobre todo del hielo del largo invierno de la paramera, y mucho nos tememos que, en la absoluta soledad de estos campos, tambien estén llamados a sufrir los efectos del inevitable vandalismo. Hablamos de daños previsibles producidos en yacimientos (o en sus infraestructuras) situados en términos municipales distintos, a los que no será fácil poner coto ni hacer frente sin compromisos previos que obliguen a todos ellos, como habrán de obligar al Ayuntamiento de Sedano a garantizar -es de esperar que reinvirtiendo lo obtenido en ella, porque el neoliberalismo apenas contempla otra opción que la del desarrollo sostenible- el correcto y regular funcionamiento del Aula Arqueológica instalada en sus dependencias. La Junta de Castilla y León ha aportado los medios necesarios para poner en marcha una iniciativa de conservación y de uso turístico de 
los dólmenes de La Lora burgalesa, gestando un proyecto vivo e imaginativo para la preservación de tan notables monumentos prehistóricos; no cabe esperar sino que los municipios beneficiarios de dichas inversiones hagan suya la iniciativa y la arropen con similares interés y esfuerzo, pero lo cierto es que al día de hoy no existe la necesaria seguridad sobre ello porque en la Comunidad de Castilla y León aún está pendiente de sistematizar el modelo de gestión de este tipo de actuaciones (Fernández Moreno y Val Recio, 1999: 335). Un problema que podría, empero, no ser grave si se tiene en cuenta la proliferación de sugerencias sobre cómo hacerlo (Campillo, 1996).

Todas las complicaciones mencionadas, relativas a la dispersión de los documentos arqueológicos del Itinerario y a la necesidad de impulsar sinergias con otros proyectos turísticos en la misma zona, y la propia responsabilidad de velar por la integridad de los valores históricos declarados, hacen aconsejable, en todo caso, que el Estado, aquí la Junta de Castilla y León, no se desvincule por completo, al menos inicialmente, de su funcionamiento, por más que la iniciativa privada en el futuro pueda ir jugando un papel cada vez más importante. Esa pretensión ya muy explícita y acaso no infundada de que el patrimonio arqueológico se convierta, de cara al turismo, en un verdadero pozo de petróleo, para nada ha de ser incompatible con una administración pública fuerte, garante de la conservación y el disfrute de unos bienes de valor contrastado más allá de su mayor o menor éxito como instrumentos de ocio (Junyent, 1999).

\section{BIBLIOGRAFÍA}

Campillo, J. (1985): "Memoria de las excavaciones realizadas en el término de Tablada de Rudrón (Burgos). El túmulo campaniforme de Tablada de Rudrón (Burgos)". Noticiario Arqueológico Hispano, 26: 7-85.

Campillo, R. (1996): "La gestión de los espacios arqueológicos protegidos". Anales de Prehistoria y Arqueología, 11-12: 303-311.

Casa, C. de la; Escribano, M.C.; Fernández, J.J. y Val, J. (1998): "La Ley de Patrimonio Histórico Español. Comentarios sobre su aplicación arqueológica en Castilla y León". Complutum, 9: 255-277.

Clark, G. y Apellániz, J.M. (1979): The North Burgos archaeological survey. Bronze and Iron Age Archaeology on the Meseta del Norte (Province of Burgos, North Central Spain). Anthropological Research Papers, 19. Arizona State University, Tempe.
CRIADO, F. (1996): "El futuro de la arqueología, ¿la arqueología del futuro". Trabajos de Pehistoria, 53: 15-35.

Corchón, M. ${ }^{a}$ S. (1989): “Datos sobre el Epipaleolítico en la Meseta Norte: La cueva del Níspero (Burgos, España)". Zephyrus, XLI-XLII: 83-101.

Delibes de CAstro, G. (1991): "Megalitos ¿Todavía una civilización de muertos?". Arqrítica. Crítica de Arqueología Española, 2 (2): 9-10.

- (1995): "Ritos funerarios, demografía y estructura social entre las comunidades neolíticas de la Submeseta Norte". En R. Fábregas, F. Pérez y C. Fernández (eds.): Arqueoloxía da Morte na Península Ibérica desde as Orixes ata o Medievo. Consellería de Cultura. Xinzo de Limia: 63-94.

Delibes, G. y Moreno, M. (e.p.): "Valredonda, escenario megalítico virtual. El dolmen de la Molina, una remembranza del Padre Ibero 80 años después". Boletín de la Institución Fernán González. Excma. Diputación de Burgos.

Delibes, G. y Rojo, M.A. (1988): "En torno al origen del foco megalítico del oriente de la Meseta: de nuevo el sepulcro de Cubillejo de Lara". Boletín del Seminario de Estudios de Arte y Arqueología, LIV: 5-24.

- (1989): "Pintura esquemática en el sepulcro de corredor burgalés de "El Moreco", Huidobro". Arqueologia (GEAP), 20: 49-54.

- (1992): "Ecos mediterráneos en los ajuares dolménicos de LaLora burgalesa". Actas del ColoquioAragónLitoral Mediterráneo. Intercambios culturales durante la Prehistoria (Zaragoza, 1991). Diputación de Aragón, Zaragoza: 383-388.

- (1997): “C-14 y secuencia megalítica en La Lora burgalesa: acotaciones a la problemática de las dataciones absolutas referentes a yacimientos dolménicos". EnA. Rodrí́guez Casal (ed.): O Neolítico Atlántico e as Orixes do Megalitismo, Xunta de Galicia. Santiago de Compostela: 391-414.

- (e.p.): "Reflexiones sobre el transfondo cultural del polimorfismo megalítico en La Lora burgalesa". Actas del I Congreso de Arqueología de Burgos. Burgos.

Delibes, G.; Rojo, M.A. y Represa, I. (1993):Dólmenes de La Lora, Burgos, Colección Guías Arqueológicas. Junta de Castilla y León. Salamanca.

Delibes, G.; Rojo, M.A. y SAnZ, C. (1986): “Dólmenes de Sedano. II. El sepulcro de corredor de Las Arnillas (Moradillo de Sedano, Burgos)". Noticiario Arqueológico Hispano, 27: 7-41.

Fernández Moreno, J.J. y Val Recio, J. (2000): "Propuestas para la divulgación del Patrimonio: la adecuación de los yacimientos y las denominadas aulas arqueológicas en Castilla y León. Ejemplos de la provincia de Soria”. En Soria Arqueológica (A José Luis Argente Oliver), 2. Diputación Provincial de Soria. Imprenta Provincial de Soria: 319-342.

Hernández Cardona, F. (1998): "La didáctica en els espais de presentació del patrimoni. Consideracions episte-

T. P., 57, n. ${ }^{\circ} 2,2000$ 
mológiques". Actes del II Seminari Arqueologia i Ensenyament (12-14 novembre 1998). Treballs d'Arqueologia, 5: 139-149.

Huidobro, L. (1957): “Descubrimiento megalítico en Nocedo Sedano)". Actas del IV Congreso Nacional deArqueología (Burgos, 1955): 125-126. Zaragoza.

JunYent, E. (1999): "Patrimoni arqueològic, difusió i mercat: algunes reflexions". Cota Zero. Revista d'Arqueologia i Ciencia, 15: 9-27.

López CAlle, C. e IlazARRA, J.A. (1997): “Condenaciones y remodelaciones. Una respuesta a la estratigrafía de los sepulcros megalíticos de Cameros". Actas del II Congreso de Arqueología Peninsular. Neolítico, Calcolítico y Bronce (Zamora, 1996): 309-321. Fundación Rei Afonso Henriques. Zamora.

MoHEn, J.P. (1980): "Aux prises avec pierres de plusieurs dizaines de tonnes". Les Dossiers de l'Archéologie, 43: 30-38.

Morales MiRAnda, J. (1998): Guía práctica para la interpretación del patrimonio. El arte de acercar el legado natural y cultural al público visitante. Ed. Empresa Pública de gestión de Programas Culturales. Junta de Andalucía. Sevilla.

Muñoz Sobrino, C.; Ramil Rego, P.; Delibes de Castro, G. y Rojo Guerra, M. (1996): "Datos paleobotánicos sobre la turbera de La Piedra (Páramo de Tozo, Burgos)". En P. Ramil-Rego, C. Fernández Rodríguez y M. Gutierrez Guitian (coord.): Biogeografía Pleistocena-Holo- cena de la Península Ibérica. Santiago de Compostela: 149-162.

Osaba, B.; AbÁsolo, J.A.; URIBARri, J.L. y Liz (1971): “El dolmen de Porquera de Butrón en la provincia de Burgos". Noticiario Arqueológico Hispano, XV: 77 -

Querol, M.A. y Martínez Díaz, B. (1996): La gestión del PatrimonioArqueológico en España. Alianza Editorial. Madrid.

RoBLEDo, C. (1954): "Descubrimiento megalítico". Boletín de la Institución Fernán González, XI: 297.

Rojo GuERrA, M.A. (1989): "El túmulo protohistórico del Paso de La Loba (Huidobro, Burgos)". Trabajos de Prehistoria, 46: 99-116.

- (1990): "Monumentos megalíticos en La Lora burgalesa: exégesis del emplazamiento". Boletín del Seminario de Estudios de Arte y Arqueología, LVI: 53-63.

- (1994): "La relación hombre/espacio en el horizontemegalítico de La Lora, Burgos”. Actas del Primer Congreso de Arqueología Peninsular (Porto, 1993). Trabalhos de Antropología e Etnología, 34 (3-4): 81-98.

Ruiz Zapatero, G. (1997): "La ciudadela ibérica de Calafell (Tarragona): un viaje al pasado". Trabajos de Prehistoria, 54(2): 175-177.

- (1998): "Fragmentos del pasado: la presentación de sitios arqueológicos y la función social de laArqueología". Actes del II Seminari Arqueologia y Ensenyament (12-14 novembre 1998). Treballs d'Arqueologia, 5: 7-34. 